\title{
Unraveling Crystalline Structure of High-Pressure Phase of Silicon Carbonate
}

\author{
Rulong Zhou, ${ }^{1}$ Bingyan Qu, ${ }^{1}$ Jun Dai, ${ }^{2}$ and Xiao Cheng Zeng ${ }^{2, *}$ \\ ${ }^{1}$ School of Science and Engineering of Materials, Hefei University of Technology, \\ Hefei, Anhui 230009, China \\ ${ }^{2}$ Department of Chemistry and Nebraska Center for Materials and Nanoscience, \\ University of Nebraska-Lincoln, Lincoln, Nebraska 68588, USA
}

(Received 13 October 2013; revised manuscript received 25 November 2013; published 3 March 2014)

\begin{abstract}
Although $\mathrm{CO}_{2}$ and $\mathrm{SiO}_{2}$ both belong to group-IV oxides, they exhibit remarkably different bonding characteristics and phase behavior at ambient conditions. At room temperature, $\mathrm{CO}_{2}$ is a gas, whereas $\mathrm{SiO}_{2}$ is a covalent solid with rich polymorphs. A recent successful synthesis of the silicon-carbonate solid from the reaction between $\mathrm{CO}_{2}$ and $\mathrm{SiO}_{2}$ under high pressure [M. Santoro et al., Proc. Natl. Acad. Sci. U.S.A. 108, 7689 (2011)] has resolved a long-standing puzzle regarding whether a $\mathrm{Si}_{x} \mathrm{C}_{1-x} \mathrm{O}_{2}$ compound between $\mathrm{CO}_{2}$ and $\mathrm{SiO}_{2}$ exists in nature. Nevertheless, the detailed atomic structure of the $\mathrm{Si}_{x} \mathrm{C}_{1-x} \mathrm{O}_{2}$ crystal is still unknown. Here, we report an extensive search for the high-pressure crystalline structures of the $\mathrm{Si}_{x} \mathrm{C}_{1-x} \mathrm{O}_{2}$ compound with various stoichiometric ratios $\left(\mathrm{SiO}_{2}: \mathrm{CO}_{2}\right)$ using an evolutionary algorithm. Based on the low-enthalpy structures obtained for each given stoichiometric ratio, several generic structural features and bonding characteristics of $\mathrm{Si}$ and $\mathrm{C}$ in the high-pressure phases are identified. The computed formation enthalpies show that the $\mathrm{SiC}_{2} \mathrm{O}_{6}$ compound with a multislab three-dimensional (3D) structure is energetically the most favorable at $20 \mathrm{GPa}$. Hence, a stable crystalline structure of the elusive $\mathrm{Si}_{x} \mathrm{C}_{1-x} \mathrm{O}_{2}$ compound under high pressure is predicted and awaiting future experimental confirmation. The $\mathrm{SiC}_{2} \mathrm{O}_{6}$ crystal is an insulator with elastic constants comparable to typical hard solids, and it possesses nearly isotropic tensile strength as well as extremely low shear strength in the 2D plane, suggesting that the multislab 3D crystal is a promising solid lubricant. These valuable mechanical and electronic properties endow the $\mathrm{SiC}_{2} \mathrm{O}_{6}$ crystal for potential applications in tribology and nanoelectronic devices, or as a stable solid-state form for $\mathrm{CO}_{2}$ sequestration.
\end{abstract}

DOI: 10.1103/PhysRevX.4.011030

Subject Areas: Materials Science

\section{INTRODUCTION}

Carbon dioxide is one of the most common molecules broadly present in the Universe. It is a dominant component of the atmosphere of Earth-like planets and exists in icy forms in outer planets and asteroids. The increase of the amount of $\mathrm{CO}_{2}$ in the atmosphere of Earth is becoming a challenge to human life. At ambient conditions, $\mathrm{CO}_{2}$ exists in a gas state, while under slightly higher pressure, it transforms into several possible molecular crystalline polymorphs such as dry ice $\left(\mathrm{CO}_{2}-\mathrm{I}\right), \mathrm{CO}_{2}$-III, and $\mathrm{CO}_{2}$-VII [1-3]. Under increasing pressure, the molecular crystal phases of $\mathrm{CO}_{2}$ can transform into extended covalent solids with crystalline structures similar to silica $\left(\mathrm{SiO}_{2}\right)$, such as $\mathrm{CO}_{2}$-V [4-11], $\mathrm{CO}_{2}$-VI [12,13], coesitelike $\mathrm{CO}_{2}\left(c-\mathrm{CO}_{2}\right)$ $[14,15]$, or amorphous silicalike $a-\mathrm{CO}_{2}[16,17]$. In most of these extended covalent solids, the carbon atoms are in tetrahedral coordination bonded with four oxygen atoms.

xzeng1@unl.edu

Published by the American Physical Society under the terms of the Creative Commons Attribution 3.0 License. Further distribution of this work must maintain attribution to the author(s) and the published article's title, journal citation, and DOI.
These extended covalent $\mathrm{CO}_{2}$ solids formed at high pressures exhibit unique properties, such as high hardness, high energy density, high thermal conductivity, high melting temperatures, etc. $[4,5]$. However, they can only stably exist under high pressure and will transform into the gas phase under ambient conditions, which strongly limits their applications.

As an isoelectronic group-IV-oxide counterpart, $\mathrm{SiO}_{2}$ is notably different from $\mathrm{CO}_{2}$. At the ambient condition, $\mathrm{SiO}_{2}$ exists only as a covalent solid with rich crystalline polymorphs such as quartz, cristobalite, coesite, etc. [18]. In all of these $\mathrm{SiO}_{2}$ crystalline polymorphs, each $\mathrm{Si}$ atom is in tetrahedral coordination surrounded by four $\mathrm{O}$ atoms, forming a $\mathrm{SiO}_{4}$ tetrahedral motif. Considering the structural similarity between the $\mathrm{SiO}_{2}$ crystalline polymorphs and the nonmolecular crystalline polymorphs of $\mathrm{CO}_{2}$ at high pressure, it is expected that the high-pressure crystalline phase of $\mathrm{CO}_{2}$ can be stabilized to ambient conditions by doping with $\mathrm{Si}$ atoms. A pioneer theoretical study was performed by Aravindh et al. [19] to evaluate, using density-functional-theory calculations, whether it is possible to stabilize the carbon-based oxide compound at ambient conditions by mixing $\mathrm{SiO}_{2}$ and $\mathrm{CO}_{2}$ tetrahedral structures. The $\beta$-cristobalite-like structures with different 
$\mathrm{Si}: \mathrm{C}$ ratios were considered in their calculations. They predicted that the $\mathrm{Si}_{x} \mathrm{C}_{1-x} \mathrm{O}_{2}$ compound may exist stably at ambient conditions at a certain composition $x$. However, the calculated formation energies for all the structures predicted are positive, indicating that the predicted structures are all metastable thus far. Recently, Santoro et al. [20] successfully synthesized a silicon-carbonate phase through the reaction between $\mathrm{CO}_{2}$ and $\mathrm{SiO}_{2}$ under highpressure conditions, which demonstrates that it is possible to synthesize various crystalline phases of $\mathrm{Si}_{x} \mathrm{C}_{1-x} \mathrm{O}_{2}$ compounds in the laboratory.

Although the solid phase of $\mathrm{Si}_{x} \mathrm{C}_{1-x} \mathrm{O}_{2}$ is fabricated in the laboratory, the detailed atomic structure of the solids has not been discerned from the experiment. More recently, Morales-García et al. studied the structure and stability of the $\mathrm{Si}_{x} \mathrm{C}_{1-x} \mathrm{O}_{2}$ compound based on first-principles calculations [21] and computed the relative energies of different metastable structures of various stoichiometries. $\mathrm{Si}_{1} \mathrm{C}_{2} \mathrm{O}_{6}$ was predicted to be the most likely stoichiometry on the basis of an analogy with the $\mathrm{UB}_{2} \mathrm{O}_{6}$ structure (where $\mathrm{U}$ atoms are substituted by $\mathrm{Si}$ atoms, and $\mathrm{B}$ atoms are substituted by $\mathrm{Si}$ or $\mathrm{C}$ atoms). Their predicted structure of $\mathrm{Si}_{1} \mathrm{C}_{2} \mathrm{O}_{6}$, however, is speculative due to the lack of a global search. Hence, a global structural search of low-enthalpy structures of the $\mathrm{Si}_{x} \mathrm{C}_{1-x} \mathrm{O}_{2}$ compounds would aid in the ultimate determination of the solid structures from the experiment. Computed mechanical, thermal, and electronic properties of the highly stable $\mathrm{Si}_{x} \mathrm{C}_{1-x} \mathrm{O}_{2}$ compound will also benefit future applications of the silicon-carbonate material. Toward this end, we have performed an extensive search for low-enthalpy structures of silicon carbonate with various stoichiometric $\mathrm{SiO}_{2} / \mathrm{CO}_{2}$ ratios using an ab initio evolutionary algorithm. We find that under 20-GPa hydrostatic pressure, $s p^{2}$ hybridization is more favored than $\mathrm{sp}$ and $s p^{3}$ hybridization for $\mathrm{C}$ atoms in highly stable siliconcarbonate solids regardless of the stoichiometric $\mathrm{SiO}_{2} / \mathrm{CO}_{2}$ ratio. Meanwhile, high coordination, especially the sixfold coordination, is more favored for $\mathrm{Si}$ atoms in these stable silicon-carbonate solids. For the $\mathrm{SiO}_{2}$-rich solids, lowsymmetry three-dimensional (3D) structures are energetically more favorable, in general, while in the $\mathrm{CO}_{2}$-rich ones, multilayered 3D structures have lower enthalpy, in general. The calculated formation enthalpies indicate that only the $\mathrm{Si}_{1} \mathrm{C}_{2} \mathrm{O}_{6}$ compound can be formed through the reaction between $\mathrm{CO}_{2}$ and $\mathrm{SiO}_{2}$ under 20-GPa pressure, and it can maintain its stability under the high pressure. The most stable crystalline structure of the $\mathrm{SiC}_{2} \mathrm{O}_{6}$ compound is predicted to be a slablike (layered) structure. We also compute the electronic structures, elastic modulus, tensile strength, and shear strength of the $\mathrm{SiC}_{2} \mathrm{O}_{6}$ crystal and assess its thermal stability through an ab initio moleculardynamics (AIMD) simulation at various high temperatures. Our calculations suggest that the $\mathrm{SiC}_{2} \mathrm{O}_{6}$ crystal is an insulator with a wide indirect band gap, and its elastic constants are comparable to typical hard solids. It also possesses nearly isotropic tensile strength as well as extremely low shear strength. The crystal can maintain its stability under high temperatures up to $2300 \mathrm{~K}$. These remarkable properties render a $\mathrm{SiC}_{2} \mathrm{O}_{6}$ solid with potential applications in nanoelectronic devices or as a high-quality solid lubricant under an extreme environment.

\section{COMPUTATIONAL METHOD}

The unbiased structural search for silicon-carbonate solids is performed using the USPEX package based on an evolutionary algorithm that has been proven to be reliable in identifying new high-pressure phases of a number of systems [22-25]. $\mathrm{SiO}_{2} / \mathrm{CO}_{2}$ ratios ranging from $4: 1\left[\left(\mathrm{SiO}_{2}\right)_{4}\left(\mathrm{CO}_{2}\right)_{1}\right]$ to $1: 3\left[\left(\mathrm{SiO}_{2}\right)_{1}\left(\mathrm{CO}_{2}\right)_{3}\right]$ are considered. Unit cells containing the number of atoms (up to 30 atoms) reflecting the chemical formulas for each given stoichiometric $\mathrm{SiO}_{2} / \mathrm{CO}_{2}$ ratio are adopted. The structural search is carried out for all solids under strong compression, i.e., under a high pressure of $20 \mathrm{GPa}$. This pressure is close to the reactive pressure of $\mathrm{SiO}_{2}$ and $\mathrm{CO}_{2}$ implemented in the experiment [20].

All low-enthalpy crystalline phases derived from the structural search are reoptimized at a higher level of theory using the VASP 5.3 package [26]. Here, the Perdew-BurkeEnzerhof (PBE) [27] exchange-correlation functional within the generalized gradient approximation is adopted. An all-electron plane-wave basis set with an energy cutoff of $520 \mathrm{eV}$ is used along with the projector-augmented-wave pseudopotential. In addition, the phonon spectra of the lowest-enthalpy structures for each given stoichiometric $\mathrm{SiO}_{2} / \mathrm{CO}_{2}$ ratio are calculated using the VASP/PHONOPY [28] package to ensure that the solid structures are truly stable (without showing imaginary phonon frequencies).

\section{RESULTS AND DISCUSSION}

\section{A. Low-enthalpy structures under 20 GPa}

$$
\text { 1. }\left(\mathrm{SiO}_{2}\right)_{4}\left(\mathrm{CO}_{2}\right)_{1}
$$

For the stoichiometric ratio $\mathrm{SiO}_{2}: \mathrm{CO}_{2}=4: 1$, two stable low-enthalpy structures are obtained. Both structures are monoclinic crystals with $\mathrm{Cm}$ (space group 8 ) and $\mathrm{C} 2$ (space group 5) symmetry, respectively. For convenience, we name the two solids 4/1-I and 4/1-II, respectively. [See Fig. 1 for atomic structures.]

In the 4/1-I structure, each $\mathrm{C}$ atom is bonded with four $\mathrm{O}$ atoms, forming a common $s p^{3}$-hybridized local structure. Among the four $\mathrm{C}-\mathrm{O}$ bonds, one is shorter $(1.33 \AA)$ and one is longer $(1.45 \AA)$ than the other two (1.40 and $1.40 \AA)$, resulting in two sets of bond angles, i.e., approximately $99^{\circ}$ or $115^{\circ}$. Each $\mathrm{Si}$ atom is bonded with six $\mathrm{O}$ atoms, forming an octahedron where the $\mathrm{Si}$ lies in the center while the six O atoms are located at vertices, respectively. There are two types of octahedron that are orientated in different directions. Among O atoms, 20\% of them are in the twofold 
(a)

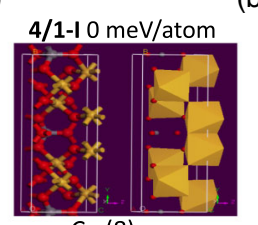

$\mathrm{Cm}(8)$

4/1-II $37 \mathrm{meV} /$ atom

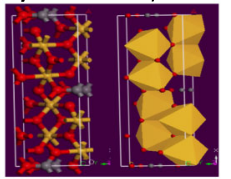

C2(5)

(c)

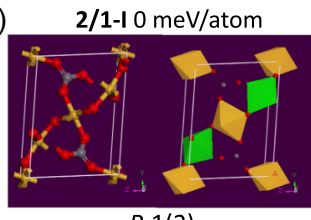

$P-1(2)$ (b)

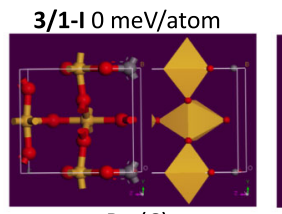

$\operatorname{Pm}(6)$
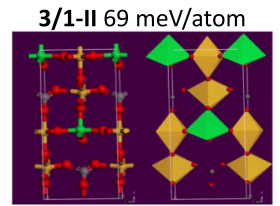

$\mathrm{Cm}(8)$

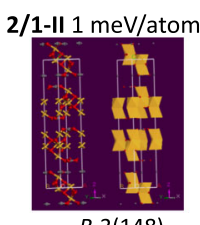

$R-3(148)$
3/1-III $75 \mathrm{meV} /$ atom

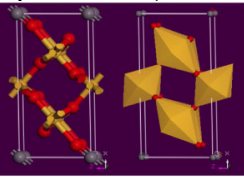

$P 2 / m(10)$

3/1-IV $96 \mathrm{meV} / \mathrm{atom}$

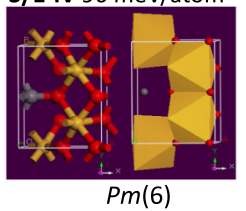

FIG. 1 (color online). Low-enthalpy structures of the (a) $\left(\mathrm{SiO}_{2}\right)_{4}\left(\mathrm{CO}_{2}\right)_{1}$, (b) $\left(\mathrm{SiO}_{2}\right)_{3}\left(\mathrm{CO}_{2}\right)_{1}$, and (c) $\left(\mathrm{SiO}_{2}\right)_{2}\left(\mathrm{CO}_{2}\right)_{1}$ compounds, respectively. Atoms in gold, grey, and red colors are $\mathrm{Si}, \mathrm{C}$, and $\mathrm{O}$, respectively.

coordination, while the other $80 \%$ are in the threefold coordination.

Solid 4/1-II is $37 \mathrm{meV} /$ atom higher in total energy than 4/1-I and hence energetically less favorable. Each $\mathrm{C}$ atom in 4/1-II is largely in $s p^{2}$ hybridization, as opposed to $s p^{3}$ hybridization in 4/1-I. The bond lengths of all three C-O bonds are approximately $1.29 \AA$, and the bond angles are the nearly ideal angle $120^{\circ}$. The chemical bonding of a Si atom in 4/1-II is similar to that in 4/1-I. Again, there are two types of Si-O octahedron. Moreover, similar to 4/1-I, $20 \%$ of the $\mathrm{O}$ atoms in 4/1-II are in the twofold coordination. Because there are fewer $\mathrm{O}-\mathrm{C}$ bonds in 4/1-II than in 4/1-I, there should be more O-Si bonds in 4/1-II since the percentages of the twofold-coordinated and threefold-coordinated $\mathrm{O}$ atoms in 4/1-II and 4/1-I structures are the same. It is known that the $\mathrm{O}-\mathrm{C}$ bond is generally stronger than the $\mathrm{O}-\mathrm{Si}$ bond. Hence, one reason that $4 / 1-\mathrm{II}$ is energetically less favorable than $4 / 1-\mathrm{I}$ is that the former has more $\mathrm{O}-\mathrm{Si}$ bonds but fewer $\mathrm{O}-\mathrm{C}$ bonds.

For $\mathrm{SiO}_{2}$, it is known that the stishovite structure is more stable at high pressure beyond $9 \mathrm{GPa}$, in which $\mathrm{Si}$ atoms and $\mathrm{O}$ atoms are sixfold and threefold coordinated, respectively. On the other hand, the extended covalent structures of $\mathrm{CO}_{2}$, where the $\mathrm{C}$ atoms are in fourfold coordination, can only be obtained under ultrahigh pressures above $40 \mathrm{GPa}$. Hence, for the structures of the $\mathrm{Si}_{x} \mathrm{C}_{1-x} \mathrm{O}_{2}$ compound under $20 \mathrm{GPa}$, one expects that the sixfold coordination and the less-than-fourfold coordination are most likely for Si and C atoms, respectively, and the percentage of twofold or threefold coordination for $\mathrm{O}$ would be determined by the coordination of Si and $\mathrm{C}$ atoms, subjecting it to Pauling's

second rule. In the $\mathrm{SiO}_{2}$-rich cases, the coordination of $\mathrm{Si}$ atoms should play a more important role for the stability of structures, while in the $\mathrm{CO}_{2}$-rich cases, $\mathrm{C}$ atoms should become more important. Hence, for $\left(\mathrm{SiO}_{2}\right)_{4}\left(\mathrm{CO}_{2}\right)_{1}$, it makes physical sense that all the $\mathrm{Si}$ atoms are in sixfold coordination while more $\mathrm{O}$ atoms are in threefold coordination. According to Pauling's second rule, $\mathrm{C}$ atoms tend to form higher coordination to allow more $\mathrm{O}$ atoms to be in threefold coordination, which is possibly the main reason that 4/1-I is energetically more stable than 4/1-II.

\section{2. $\left(\mathrm{SiO}_{2}\right)_{3}\left(\mathrm{CO}_{2}\right)_{1}$}

For the stoichiometric ratio $\mathrm{SiO}_{2}: \mathrm{CO}_{2}=3: 1$, four lowenthalpy structures are identified and named 3/1-I to 3/1-IV, respectively [see Fig. 1], according to their ranking in relative energies. All four solids are monoclinic crystals with $P m(6), C m(8), P 2 / m(10)$, and $P m(6)$ space-group symmetries, respectively.

In 3/1-I, the $\mathrm{C}$ atoms are in the $s p^{2}$ hybridization and each $\mathrm{C}$ is bonded with three $\mathrm{O}$ atoms. Among the three $\mathrm{C}-\mathrm{O}$ bonds, one is $1.31 \AA$ and the other two are $1.26 \AA$. The three bond angles are close to the ideal angle $120^{\circ}$. Each $\mathrm{Si}$ atom in 3/1-I is also in sixfold coordination and bonded with six $\mathrm{O}$ atoms. Two types of Si-centered octahedrons are also seen in 3/1-I, and they are aligned almost vertically. For O atoms, $50 \%$ of them are in twofold coordination while the other $50 \%$ are in threefold coordination.

The 3/2-II structure is very different from those of 3/1-I and $4 / 1$. The total energy is $69 \mathrm{meV} /$ atom higher than 3/1-I. In 3/1-II, carbon atoms are in the same $s p^{2}$ hybridization as in 3/1-I. The bond lengths of two C-O bonds are $1.27 \AA$, and that of the third one is $1.26 \AA$, close to those in 3/1-I. The three bond angles are also close to the ideal angle $120^{\circ}$. The major difference between 3/1-II and 3/1-I is the bonding of Si atoms [see Fig. 1]. Apparently, there are two distinctive bonding types for $\mathrm{Si}$ atoms. Besides the sixfold-coordinated $\mathrm{Si}$ atoms, $33.3 \%$ of $\mathrm{Si}$ atoms are in the fivefold coordination [highlighted in green in Fig. 1]. Among the sixfold-coordinated Si atoms, there are still two different types of octahedron formed. Thus, in 3/1-II, Si atoms as well as the bonded $\mathrm{O}$ atoms form three types of polyhedron, two differently aligned octahedrons, and one hexahedron. For $\mathrm{O}$ atoms, 50\% are in twofold coordination while another $50 \%$ are in threefold coordination. The lower stability of 3/1-II compared to 3/1-I is likely due to the presence of fivefold-coordinated $\mathrm{Si}$ atoms.

$3 / 1-\mathrm{III}$ is $75 \mathrm{meV} /$ atom higher in energy than $3 / 1-\mathrm{I}$. The major difference between the structure of 3/1-III and 3/1-I is that the $\mathrm{C}$ atoms in 3/1-III are in twofold coordination and each is bonded with two $\mathrm{O}$ atoms. Hence, the $\mathrm{C}$ atoms are in the $s p$ hybridization. The bond length of $\mathrm{C}-\mathrm{O}$ is $1.16 \AA$, nearly the same as that in a $\mathrm{CO}_{2}$ molecule. The bonding characteristics of $\mathrm{Si}$ atoms are very similar to those in 3/1-I. The Si-O structural feature in 3/1-III is also very 
similar to 3/1-I. For $\mathrm{O}$ atoms, $50 \%$ are in twofold coordination and the other $50 \%$ in threefold coordination. Therefore, the energy difference between 3/1-III and 3/1-I is mainly attributed to the difference in the bonding characteristics of $\mathrm{C}$ atoms. In summary, below 20-GPa pressure, it appears that in silicon carbonates, $s p^{2}$ hybridization is the more favored bonding type for $\mathrm{C}$ atoms than $s p$ hybridization.

Besides the solid structures featuring either threefold or twofold coordination for $\mathrm{C}$ atoms, we also find a stable structure (3/1-IV) in which the $\mathrm{C}$ atoms are in fourfold coordination. The energy of $3 / 1-\mathrm{IV}$ is $96 \mathrm{meV} / \mathrm{atom}$ higher than 3/1-I. The bond lengths of $\mathrm{C}-\mathrm{O}$ are close to those in 4/1-I, except that one is a bit longer (1.50 $\AA$ in $3 / 1$-IV versus $1.45 \AA$ in $4 / 1-I)$. All the $\mathrm{Si}$ atoms are also in sixfold coordination, and again, there are two types of octahedron for Si-O local units. Octahedrons of the first type are connected with each other, forming an octahedron chain. Octahedrons of the second type are separated from one another by $\mathrm{C}$ atoms. Only $25 \%$ of $\mathrm{O}$ atoms are in twofold coordination, while $75 \%$ are in threefold coordination. Notice that the energy of 3/1-IV is much higher than that of $3 / 1-\mathrm{I}$, so, starting from the stoichiometric ratio $\mathrm{SiO}_{2}: \mathrm{CO}_{2}=3: 1$, fourfold coordination is no longer favored for $\mathrm{C}$.

\section{3. $\left(\mathrm{SiO}_{2}\right)_{2}\left(\mathrm{CO}_{2}\right)_{1}$}

For the stoichiometric ratio $\mathrm{SiO}_{2}: \mathrm{CO}_{2}=2: 1$, we obtain three low-enthalpy solids with dramatically different structures [Fig. 1]. The lowest-enthalpy structure (2/1-I) is a triclinic crystal with P-1(2) space-group symmetry. The C atoms are in threefold coordination. The bond lengths of the three $\mathrm{C}-\mathrm{O}$ bonds for each $\mathrm{C}$ atom are 1.26, 1.28, and $1.30 \AA$, respectively. There are two sets of $\mathrm{Si}$ atoms similar to those in 3/1-II: $50 \%$ of the $\mathrm{Si}$ atoms are in sixfold coordination, and another $50 \%$ are in fivefold coordination. There are also two types of octahedron aligned in different orientations, both formed by the first set of $\mathrm{Si}$ atoms. The percentages of twofold-coordinated $\mathrm{O}$ atoms and threefoldcoordinated $\mathrm{O}$ atoms are $66.7 \%$ and $33.3 \%$, respectively.

The second low-lying structure (2/1-II) is a multislab 3D structure and nearly degenerate in energy as 2/1-I (only $1 \mathrm{meV} /$ atom in energy difference). $2 / 1-\mathrm{II}$ is a trigonal crystal with high symmetry [R-3(148)]. There are three slabs in one unit cell. In each slab, the $\mathrm{C}$ atoms are located in the top and bottom layers and the $\mathrm{Si}$ atoms are located in the central layer. Each $\mathrm{C}$ atom is in the $s p^{2}$ hybridization. The C-O bond is $1.29 \AA$. All the $\mathrm{Si}$ atoms are in sixfold coordination. Three layers of octahedrons formed by $\mathrm{Si}$ and the surrounding $\mathrm{O}$ atoms are present in each slab. For $\mathrm{O}$ atoms, $50 \%$ are in twofold coordination and the other 50\% in threefold coordination, as in 2/1-I.

The third structure (2/1-III) is a monoclinic crystal with $P 2_{1}(4)$ space-group symmetry. It is $30 \mathrm{meV} /$ atom higher in energy than 2/1-I. Similarly to 3/1-III, all the $\mathrm{C}$ atoms in $2 / 1-$ III are in twofold coordination. For the two $\mathrm{O}$ atoms bonded with a $\mathrm{C}$ atom, one is also bonded with a $\mathrm{Si}$ atom while the other is not. The bond lengths of the two C-O bonds are 1.18 and $1.16 \AA$, respectively. The O-C-O angle is $163^{\circ}$, differing from that $\left(180^{\circ}\right)$ in $3 / 1$-III. The Si-O frame in $2 / 1$-III is very close to that in $3 / 1$-III. For $\mathrm{O}$ atoms, $16.7 \%$ are in single coordination, $33.3 \%$ in twofold coordination, and $50 \%$ in threefold coordination.

\section{4. $\left(\mathrm{SiO}_{2}\right)_{1}\left(\mathrm{CO}_{2}\right)_{1}$}

For the stoichiometric ratio $\mathrm{SiO}_{2}: \mathrm{CO}_{2}=1: 1$, four stable low-enthalpy crystalline structures are found. The lowest-enthalpy structure (1/1-I) is a triclinic crystal belonging to the $\mathrm{P}-1(2)$ space group. The second structure $(1 / 1-\mathrm{II})$ is a monoclinic crystal belonging to the $P 2_{1}(4)$ space group, and its total energy is very close to $1 / 1-\mathrm{I}$. The third structure (1/1-III) is also a monoclinic crystal with $P 2_{1} / m(11)$ space-group symmetry. The last one (1/1-IV) is a tetragonal crystal belonging to the I-4(82) space group. All the $\mathrm{Si}$ and $\mathrm{C}$ atoms in 1/1-IV form tetrahedral structures, and are all bonded with $\mathrm{O}$ atoms.

As shown in Fig. 2, each C atom in 1/1-I is bonded with three $\mathrm{O}$ atoms, manifesting typical $s p^{2}$ hybridization. The bond lengths of three C-O bonds are 1.26, 1.27, and $1.30 \AA$, as in the most stable structures with other stoichiometric ratios. All the $\mathrm{Si}$ atoms are in sixfold coordination and bonded with only $\mathrm{O}$ atoms. Contrary to most other stable structures with different stoichiometric ratios, in the 1/1-I structure, only one type of octahedron formed by $\mathrm{Si}$ and the surrounding $\mathrm{O}$ atoms is seen. For $\mathrm{O}$ atoms, $75 \%$ are in twofold coordination while $25 \%$ are in threefold coordination. With this stoichiometric ratio, the number of twofold-coordinated $\mathrm{O}$ atoms is more than that of the threefold-coordinated ones in the most stable structure. Hence, $\mathrm{C}$ atoms will play a more important role in making more stable structures.

The structure of $1 / 1-\mathrm{II}$ is very close to $1 / 1-\mathrm{I}$, except the relative orientation of the $s p^{2}$ planes of $\mathrm{C}$ atoms. In 1/1-I, the two $\mathrm{C} s p^{2}$ planes in one unit cell are parallel with each other, while in 1/1-II, they are normal to each other. The $\mathrm{Si}-\mathrm{O}$ frames in both structures are almost the same. Hence, $1 / 1$-II and $1 / 1$-I are very close in total energies.

In 1/1-III, the $\mathrm{C}$ atoms are also in threefold coordination and the $\mathrm{Si}$ atoms are in sixfold coordination, as in 1/1-I and $1 / 1$-II. However, because $50 \%$ of $\mathrm{O}$ atoms are in threefold coordination, a percentage much higher than those in 1/1-I and 1/1-II, I-III is energetically less favorable than $1 / 1-\mathrm{I}$ and $1 / 1-$ II.

Last, in 1/1-IV, all $\mathrm{C}$ and $\mathrm{Si}$ atoms are in fourfold coordination [see Fig. 2]. All the $\mathrm{O}$ atoms are in twofold coordination, and each $\mathrm{O}$ is bonded with one $\mathrm{C}$ and one $\mathrm{Si}$ atom. 1/1-IV is $154 \mathrm{meV} /$ atom higher in energy than 1/1-I. A similar tetrahedral structure to 1/1-IV has been previously studied by Aravindh et al. [19]. It was shown that the tetrahedral structure of silicon carbonate is not energetically favorable even under $20 \mathrm{GPa}$, which is the reason 
(a)

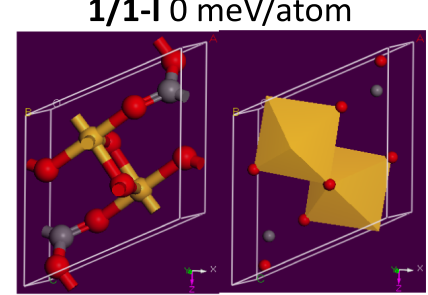

$P-1(2)$

1/1-III $92 \mathrm{meV} /$ atom

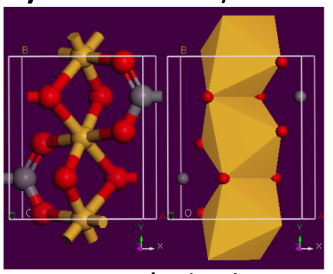

$P 2_{1} / m(11)$
1/1-II $9 \mathrm{meV} /$ atom

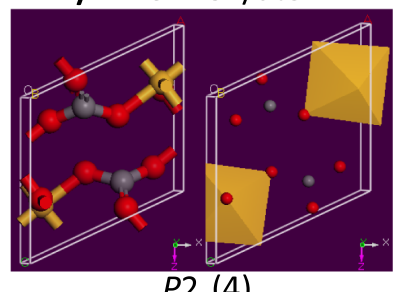

$P 2_{1}(4)$

1/1.IV $154 \mathrm{meV} /$ atom

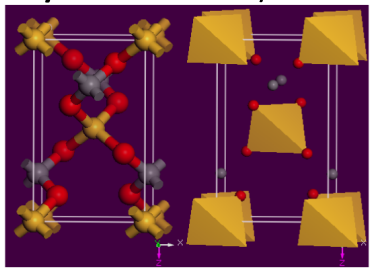

I-4(82) (c)

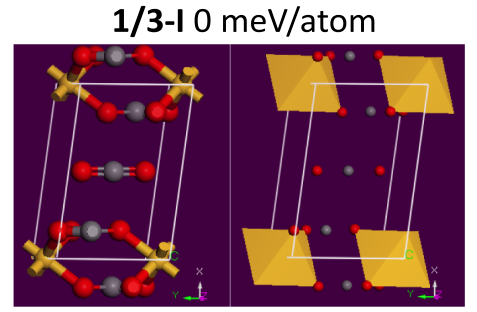

P-1(2)

1/3-II $1 \mathrm{meV} /$ atom

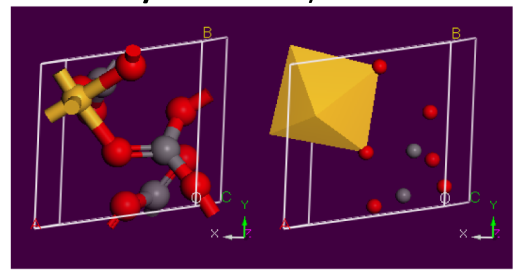

$P 1(1)$ (b)

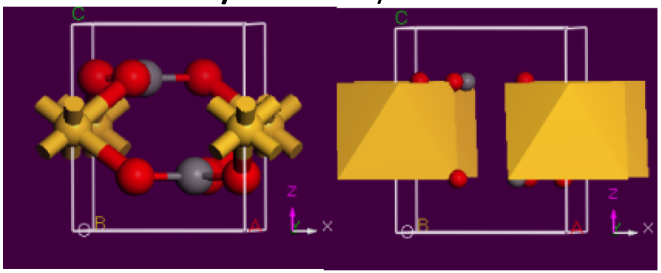

P-3(147)

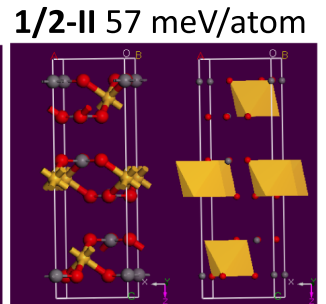

$R-3(148)$
1/2-III $132 \mathrm{meV} /$ atom

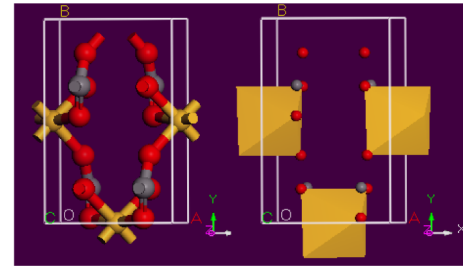

C2(5)

FIG. 2 (color online). Low-enthalpy structures of the (a) $\left(\mathrm{SiO}_{2}\right)_{1}\left(\mathrm{CO}_{2}\right)_{1}$, (b) $\left(\mathrm{SiO}_{2}\right)_{1}\left(\mathrm{CO}_{2}\right)_{2}$, and $(\mathrm{c})(\mathrm{SiO})_{1}\left(\mathrm{CO}_{2}\right)_{3}$ compounds, respectively.

why Aravindh et al. [19] found that their formation enthalpies are always positive. Besides 1/1-IV, another structure is also found in which all $\mathrm{C}$ atoms are in fourfold coordination. In that structure, the $\mathrm{Si}$ atoms are in sixfold coordination, as in $1 / 1-\mathrm{I}$ to $1 / 1-$ III. Note that the total enthalpy of the second tetrahedral structure is $18 \mathrm{meV} / \mathrm{atom}$ lower than 1/1-IV. Thus, under high pressure, the sixfold coordination seems more preferred by $\mathrm{Si}$ atoms than the fourfold coordination.

\section{5. $\left(\mathrm{SiO}_{2}\right)_{1}\left(\mathrm{CO}_{2}\right)_{2}$}

As discussed above, for the silicon carbonate with either richer $\mathrm{SiO}_{2}$ composition or equal composition of $\mathrm{SiO}_{2}$ and $\mathrm{CO}_{2}$, almost all the lowest-enthalpy stable structures are 3D structures with low space-group symmetries [except $\left(\mathrm{SiO}_{2}\right)_{2}\left(\mathrm{CO}_{2}\right)_{1}$, for which the layered structure and the 3D structure are almost degenerate in energy]. However, the situation changes when the $\mathrm{CO}_{2}$ component is richer. For the stoichiometric ratio $\mathrm{SiO}_{2}: \mathrm{CO}_{2}=1: 2$, the lowestenthalpy structure is a trigonal multilayered structure (1/2-I) with the P-3(147) space group [see Fig. 2]. In $1 / 2$-I, each slab contains three atomic layers, where the top and bottom layers are composed of $\mathrm{C} s p^{2}$ planes and the central layer is composed of $\mathrm{Si}$ octahedrons. Each $\mathrm{Si}$ atom is bonded with three $\mathrm{O}$ atoms in both the top and bottom layers. In 1/2-I, the $\mathrm{C}, \mathrm{Si}$, and $\mathrm{O}$ atoms are in threefold, sixfold, and twofold coordination, respectively.

The second structure (1/2-II) obtained is also a multislab structure. There are three slabs in one unit cell. In each slab, the atomic structure is the same as that in 1/2-I. The main difference between the two solids is that the relative position between neighboring slabs is different. However, $1 / 2$-II is energetically much less favorable (57 meV/atom higher in energy) than 1/2-I. As shown in Fig. 2, in 1/2-II, each $\mathrm{C}$ atom in the bottom layer of the top slab is exactly in registry with that in the top layer of the bottom slab, while in 1/2-I, the C atoms in the bottom layer of the top slab and those in the top layer of the bottom slab are out of registry. Surprisingly, such a small structural difference results in a significant difference in the total enthalpy $(57 \mathrm{meV} /$ atom higher in energy than 1/2-I).

The lowest-enthalpy $3 \mathrm{D}$ structure for $\mathrm{SiO}_{2} / \mathrm{CO}_{2}=1: 2$ is a monoclinic crystal with $\mathrm{C} 2(5)$ space-group symmetry (1/2-III). It is $132 \mathrm{meV} /$ atom higher in energy than $1 / 2$-I. In 1/2-III, all the $\mathrm{C}$ atoms are in the $s p^{2}$ hybridization, the $\mathrm{Si}$ atoms are in sixfold coordination, and all the $\mathrm{O}$ atoms are in twofold coordination.

$$
\text { 6. }\left(\mathrm{SiO}_{2}\right)_{1}\left(\mathrm{CO}_{2}\right)_{3}
$$

For the stoichiometric ratio $\mathrm{SiO}_{2}: \mathrm{CO}_{2}=1: 3, \mathrm{C}$ atoms in the lowest-enthalpy structure $1 / 3-\mathrm{I}$ are in the $s p$ 
hybridization [see Fig. 2]. The structure of 1/3-I can be viewed as inserting $\mathrm{CO}_{2}$ molecules into the space between two slabs in $1 / 2$-I or in $1 / 2$-II. With the added $\mathrm{CO}_{2}$, the symmetry of $1 / 3-\mathrm{I}[\mathrm{P}-1(2)]$ becomes dramatically lower than that of $1 / 2-$ I. The second low-enthalpy structure $(1 / 3-$ II) is almost degenerate in energy as $1 / 3$-I but possesses no $s p$-hybridized $\mathrm{C}$ atoms. $1 / 3$-II is only $1 \mathrm{meV} /$ atom higher in energy than 1/3-I under $20 \mathrm{GPa}$. 1/3-II is a triclinic crystal without high symmetry. In 1/3-II, all $\mathrm{C}$ atoms are in threefold coordination, all $\mathrm{Si}$ atoms are in sixfold coordination, and all $\mathrm{O}$ atoms are in twofold coordination.

In summary, under 20-GPa hydrostatic pressure, the $s p^{2}$ hybridization is energetically more favorable than the sp and $s p^{3}$ hybridization for $\mathrm{C}$ atoms in stable silicon carbonate regardless of the stoichiometric ratio $\mathrm{SiO}_{2} / \mathrm{CO}_{2}$. Coordination higher than fourfold, especially the sixfold coordination, is more favored for $\mathrm{Si}$ atoms. The $\mathrm{Si}$ atoms are not bonded with $\mathrm{C}$ atoms directly but connected with $\mathrm{C}$ atoms via the $\mathrm{O}$ atoms. In $\mathrm{SiO}_{2}$-rich compounds or compounds with equal composition of $\mathrm{SiO}_{2}$ and $\mathrm{CO}_{2}, 3 \mathrm{D}$ low-symmetry structures are normally more preferred energetically, while in $\mathrm{CO}_{2}$-rich compounds, multislab structures typically have lower enthalpy. Except for $\left(\mathrm{SiO}_{2}\right)_{1}\left(\mathrm{CO}_{2}\right)_{3}$, no $\mathrm{CO}_{2}$ molecule exists in the low-enthalpy structures; in other words, silicon-carbonate compounds are generally formed.

\section{B. Formation enthalpies}

To assess stabilities of the low-enthalpy $\mathrm{Si}_{x} \mathrm{C}_{1-x} \mathrm{O}_{2}$ compounds with respect to solid-state $\mathrm{CO}_{2}$ and $\mathrm{SiO}_{2}$ at $20 \mathrm{GPa}$, we have computed the formation enthalpies based on the definition $\Delta H=H_{\mathrm{Si}_{x} \mathrm{C}_{1-x} \mathrm{O}_{2}}-x H_{\mathrm{SiO}_{2}}-(1-x) H_{\mathrm{CO}_{2}}$. The reference structures of $\mathrm{CO}_{2}$ and $\mathrm{SiO}_{2}$ under $20 \mathrm{GPa}$ are also determined through an extensive structural search. It turns out that the lowest-enthalpy structure of $\mathrm{CO}_{2}$ under $20 \mathrm{GPa}$ is a crystalline structure with $I-42 d$ symmetry [7-9], where $\mathrm{C}$ atoms are in tetrahedral coordination, and the lowest-enthalpy structure of $\mathrm{SiO}_{2}$ is the stishovite [29] structure with $P 4_{2} / \mathrm{mnm}$ symmetry, where $\mathrm{Si}$ atoms are in sixfold coordination. The formation enthalpies as a function of the composition of $\mathrm{SiO}_{2}$ are shown in Fig. 3 . Apparently, except for $x=0.333$, i.e., $\left(\mathrm{SiO}_{2}\right)_{1}\left(\mathrm{CO}_{2}\right)_{2}$, the formation enthalpies with other compositions are all positive. For $x=0.333$, only the lowest-enthalpy structure, i.e., $1 / 2-\mathrm{I}$ [Fig. 3], gives rise to negative formation enthalpy. Hence, only the structure $1 / 2-\mathrm{I}$ is most viable and may be synthesized through a reaction of $\mathrm{SiO}_{2}$ and $\mathrm{CO}_{2}$ under $20 \mathrm{GPa}$ at low temperature. Note that our predicted stoichiometry for the lowest-formation-enthalpy structure is the same as that of Morales-García [21], although the predicted structure differs from theirs. For all other low-enthalpy structures predicted above, although they are less likely to be formed under $20 \mathrm{GPa}$ and low temperature, it is still conceptually important to know the family of metastable crystal structures and their total energies. Note that the

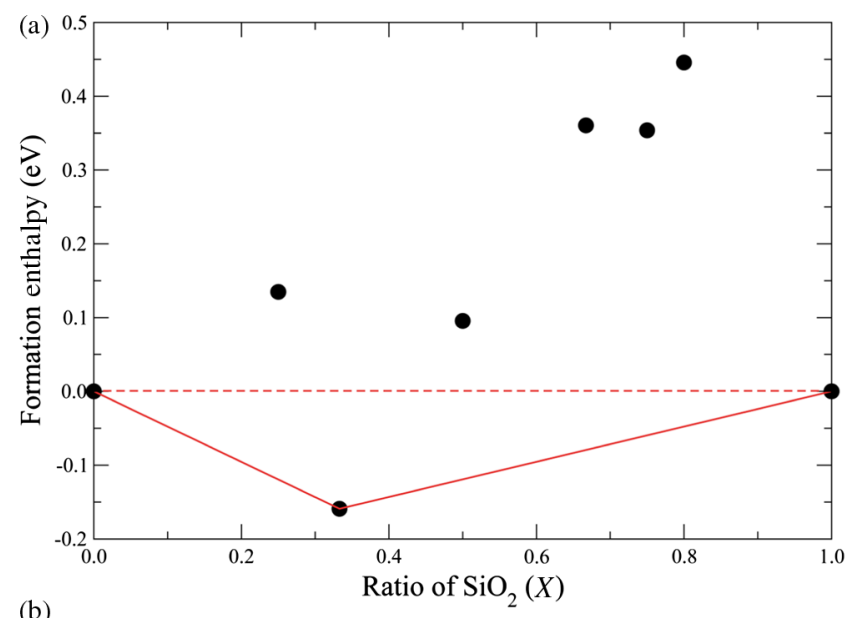

(b)

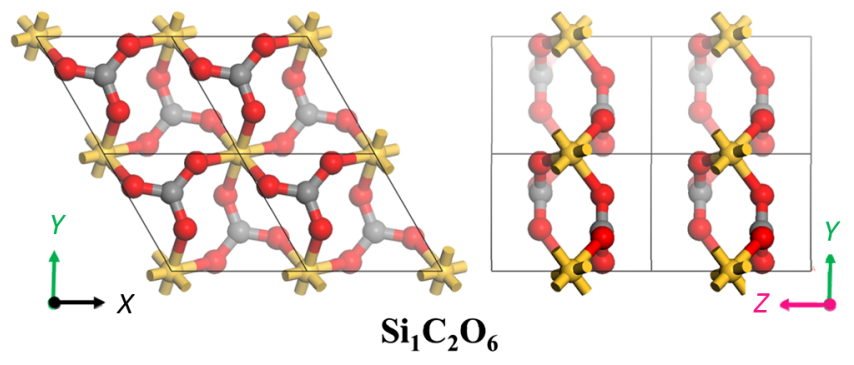

FIG. 3 (color online). (a) The formation enthalpy of the lowestenthalpy structures of $\mathrm{Si}_{x} \mathrm{C}_{1-x} \mathrm{O}_{2}$ under 20-GPa pressure as a function of $x$. (b) The detailed structure of the most stable structure of $\mathrm{Si}_{1} \mathrm{C}_{2} \mathrm{O}_{6}$.

energies of all structures are calculated at zero temperature. The positive formation energies of the structures mean that these structures are unlikely to be formed at low temperature. At higher temperatures, however, some of these metastable structures may be formed. In the experiment, several reaction paths between $\mathrm{CO}_{2}$ and $\mathrm{SiO}_{2}$ are examined at pressure and temperature of 18-26 GPa and 296-980 K [20]. As such, the silicon carbonate observed in the experiments may be not only the lowest-formation-enthalpy structure $1 / 2$-I, but it may also include other low-enthalpy structures with different stoichiometric $\mathrm{SiO}_{2} / \mathrm{CO}_{2}$ ratios.

For comparison with experiments, we compute the infrared (IR) and x-ray-diffraction (XRD) spectra for the lowest-enthalpy structure with each stoichiometric ratio using the CASTEP [30,31] and Reflex modules implemented in Materials Studio 6.1, respectively. For the CASTEP calculation, a PBE [27] functional and normconserving pseudopotentials [32] are adopted. The simulated IR and XRD spectra are displayed in Fig. 4. In the experimental XRD, there are two sharp peaks located within the range of $6^{\circ}-8^{\circ}$ for the silicalite- $\mathrm{CO}_{2}$ mixture at room temperature. The two peaks are broadened when the temperature increases and almost vanish at $723 \mathrm{~K}$. So, it is believed that a reaction between $\mathrm{CO}_{2}$ and $\mathrm{SiO}_{2}$ occurs at the high temperature. This means that the possible crystalline structures formed after the reaction may exhibit 

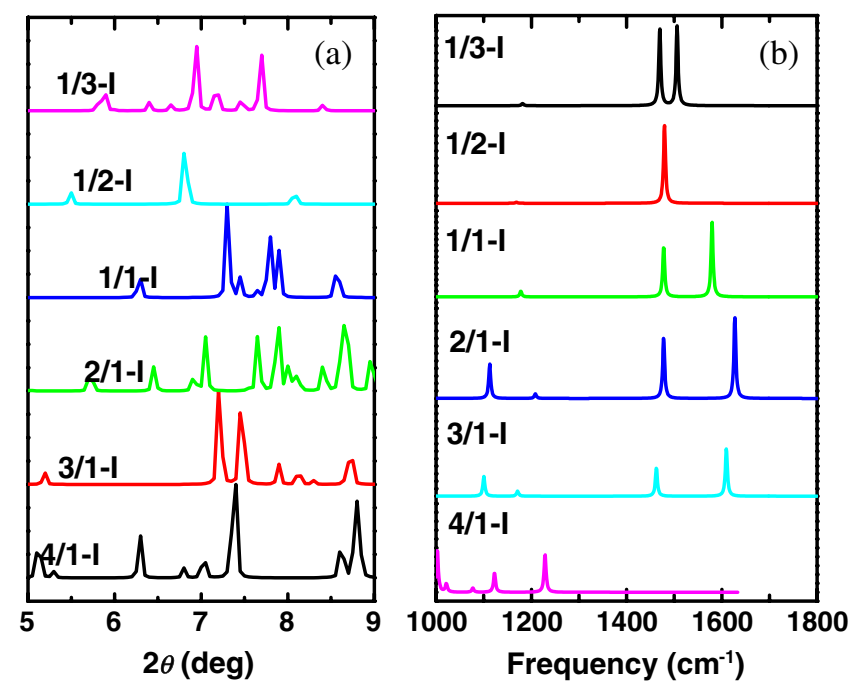

FIG. 4 (color online). The simulated (a) XRD spectra and (b) IR spectra of the most stable structure for each stoichiometric ratio.

Bragg peaks in the XRD spectra near the two sharp peaks of the silicalite- $\mathrm{CO}_{2}$ mixture; i.e., both are located in the range of $6^{\circ}-8^{\circ}$. From the simulated XRD spectra, we see clearly that for most predicted structures, there are one or several peaks in the range of $6^{\circ}-8^{\circ}$. A sum of the XRD spectra from all or several of these structures will lead to broad peaks in this range. So, a mixture of these crystalline structures may be present in the final product, although the amount may be very small.

For the IR spectra, the peaks at approximately 1500 and $\sim 1600 \mathrm{~cm}^{-1}$ detected in the experiment are due to silicon carbonate. The peaks at $1500 \mathrm{~cm}^{-1}$ are thought to be due to the vibration mode of the $\mathrm{CO}_{3}$ group in which all the $\mathrm{C}-\mathrm{O}$ bonds are single bonds. In most of the predicted structures, $\mathrm{C}$ atoms are in $s p^{2}$ hybridization and are bonded with three $\mathrm{O}$ atoms, forming three single $\mathrm{C}-\mathrm{O}$ bonds. The IR spectra of these structures appear to be consistent with the experimental measurement. In the simulated IR spectra, except for the 4/1-I structure, all other structures give rise to peaks near either 1500 or $1600 \mathrm{~cm}^{-1}$ or both. Through an analysis of the vibration corresponding to both modes, it is confirmed that the peaks near 1500 and $1600 \mathrm{~cm}^{-1}$ are due to the stretching vibration mode of $\mathrm{C}$ in the $\mathrm{CO}_{3}$ group for 3/1-I, 2/1-I, $1 / 1-\mathrm{I}$, and 1/2-I structures. For the 1/3-I structure, the two peaks around $1500 \mathrm{~cm}^{-1}$ stem from a vibration mode of $\mathrm{C}$ atoms, too, although the $\mathrm{C}$ atoms in 1/3-I are not in planar threefold coordination but in nearly linear and twofold coordination. For the structure of 4/1-I, the C atoms are all in tetrahedral coordination, and the vibration frequencies of $\mathrm{C}$ atoms are lower. Again, the simulated IR spectra are consistent with the experimental ones, suggesting that a mixture of these low-enthalpy structures may be present in the final product of the reaction between $\mathrm{CO}_{2}$ and $\mathrm{SiO}_{2}$.

\section{Properties of the most stable structure 1/2-I}

\section{Electronic properties}

The structure 1/2-I of a silicon-carbonate compound is predicted to be the most stable. Here, we focus only on the electronic and mechanical properties of $1 / 2-\mathrm{I}$. For practical applications, it is important to examine whether the structure is stable under 1-atm pressure. To this end, we calculate the phonon spectra of $1 / 2-\mathrm{I}$ under $1 \mathrm{~atm}$, as shown in Fig. 5. Clearly, there are no imaginary frequencies in the entire Brillouin zone. The structure 1/2-I can still maintain its stability if the high-pressure condition is changed to the ambient condition.

As discussed above, the structure 1/2-I is a slablike (layered) structure. The van der Waals interaction between any two labs is weak, which would not influence the electronic properties significantly unless it is metallic. Here, we focus on the electronic properties of one single slab of 1/2-I to understand how the chemical bonds of Si-O and $\mathrm{C}-\mathrm{O}$ in the slab influence the properties. The band structures as well as the projected density of states are shown in Fig. 5. Clearly, 1/2-I is an insulator with an indirect band gap. The value between the conduction-band minimum and the valence-band maximum is $4.5 \mathrm{eV}$. The direct gap at the $\Gamma$ point is $4.9 \mathrm{eV}$. It is known that the PBE functional tends to underestimate band gaps of nonmetal materials. Hence, the real band gap of $1 / 2-\mathrm{I}$ is expected to be larger. To obtain more reasonable band structures, we use the Heyd-Scuseria-Ernzerhof (HSE06) hybrid functional $[33,34]$. The newly computed indirect band gap and the direct gap at the $\Gamma$ point are 6.4 and $6.8 \mathrm{eV}$, respectively. The top of the valance band is not located at the $\Gamma$ point, as with most materials, but at the $M(0,1 / 2,0)$ and $K(-1 / 3,2 / 3,0)$ points. It is very similar to that of hexagonal boron-nitride ( $h$-BN). On the other hand, the bottom of the conduction band is located at the $\Gamma$ point, unlike the $h$-BN. The unique band structure of $1 / 2-\mathrm{I}$ is strongly dependent on the crystal structure and the bonding among $\mathrm{C}, \mathrm{Si}$, and $\mathrm{O}$ elements. From the projected density of states, we learn that the states near the tops of valance bands are mainly contributed by the $p_{x}$ and $p_{y}$ orbitals of $\mathrm{O}$, which are the main contribution to the covalent bonds of $\mathrm{C}-\mathrm{O}$ and $\mathrm{Si}-\mathrm{O}$. The lowest two conduction bands originate mainly from the $p_{z}$ orbitals of $\mathrm{C}$ and $\mathrm{O}$. Si has a slight contribution to the states in the energy window (-4-6 eV).

To examine the bonding characteristic of $\mathrm{C}-\mathrm{O}$ and $\mathrm{Si}-\mathrm{O}$ bonds in the 1/2-I structure, we calculate the electronlocalization function (ELF). The 3D isosurface of the ELF and the projected ELF on the xy plane are shown in Figs. 5(c) and 5(d), respectively. The $x y$ plane represents the lower $\mathrm{CO}_{3}$ layer. It is obvious that a small percentage of electrons is localized at the center of each $\mathrm{C}-\mathrm{O}$ bond, indicating that covalent bonds are formed between $\mathrm{C}$ and $\mathrm{O}$. Each $\mathrm{C}$ atom is bonded with three $\mathrm{O}$ atoms, and all the $\mathrm{CO}_{3}$ planar units are in the upper and lower layers of a slab, respectively, and are also connected by the central Si layer 

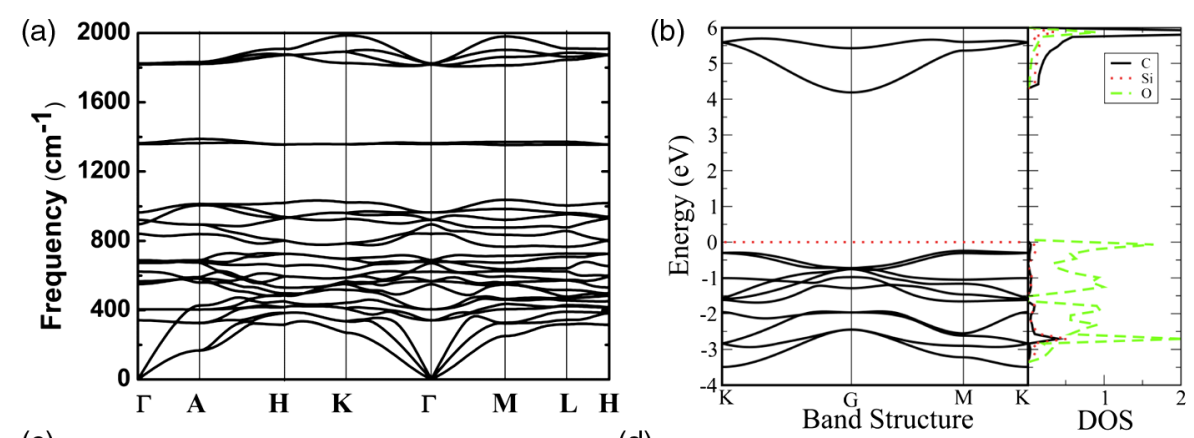

(c)
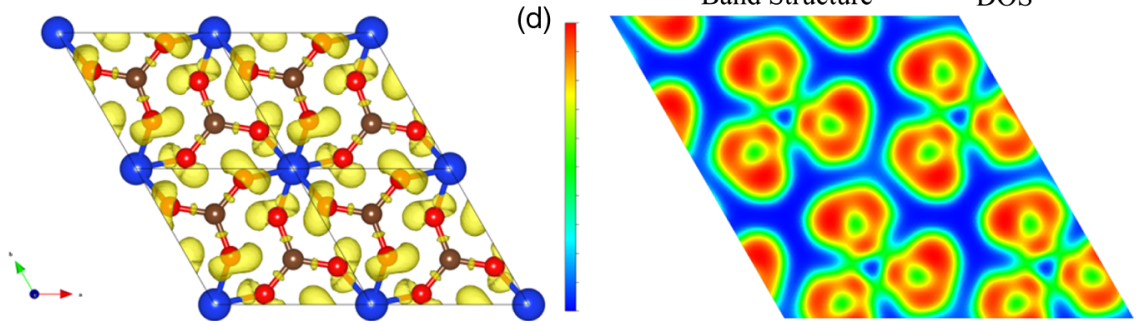

FIG. 5 (color online). (a) Computed phonon spectra of the 1/2-I structure at ambient condition. (b) The band structure and the projected density of states $[K(-1 / 3,2 / 3,0), M(0,0,1 / 2)]$. (c) The 3D ELF isosurfaces with ELF $=0.83$. (d) The 2D figure of the ELF projected on the lower $\mathrm{C}-\mathrm{O}$ layer. Color code in $(\mathrm{c})$ : red $(\mathrm{O})$, brown $(\mathrm{C})$, and blue (Si).

[Fig. 3]. Each $\mathrm{C}$ atom possesses one lone pair of electrons distributed along the $z$ direction. Besides the electrons at the center of each $\mathrm{C}-\mathrm{O}$ bond, other electrons are localized around $\mathrm{O}$ atoms. As seen in Fig. 5(c), some electrons around $\mathrm{O}$ are distributed along the $z$ direction. So, the electrons localized at the centers of $\mathrm{Si}-\mathrm{O}$ bonds cannot be clearly distinguished because the ELF of the $\mathrm{Si}-\mathrm{O}$ bond and that of the lone-pair electrons of $\mathrm{O}$ are connected. As shown by the plotted density of states, the two lowest conduction bands are mainly contributed by the $p_{z}$ orbitals of $\mathrm{C}$ and $\mathrm{O}$. Thus, the lowest two conduction bands are contributed mainly by the lone-pair electrons of $\mathrm{O}$ and $\mathrm{C}$ while the top valence bands are contributed mainly by the electrons that participate in the $\mathrm{C}-\mathrm{O}$ bonds.

\section{Mechanical properties}

As discussed above, 1/2-I has a multilayered structure, and it is also an insulator with a wide indirect band gap. With these properties, 1/2-I may be used in nanosized metal-insulator-semiconductor (MIS) devices as an intermediate insulator layer. Because of the multilayered structure, 1/2-I may also be used as a solid lubricant as the graphite. However, these potential applications demand that the 1/2-I solid possess good mechanical properties. To this end, we have computed the elastic constants, the tensile strength along the 2D plane, and the shear strength in the 2D plane, respectively, using the VASP package.

The calculated elastic constants of 1/2-I are $C_{11}=C_{22}=251.6 \mathrm{GPa}, C_{33}=22.2 \mathrm{GPa}, C_{12}=12.2 \mathrm{GPa}$, $C_{13}=C_{23}=2.3 \mathrm{GPa}, C_{44}=\mathrm{C}_{55}=2.5 \mathrm{GPa}$, and $\mathrm{C}_{66}=$ $119.7 \mathrm{GPa}$, respectively. The bulk and shear moduli are 62.1 and $61.1 \mathrm{GPa}$, respectively. The Young's moduli along the $x$ and $y$ directions are both $245.8 \mathrm{GPa}$. The values of
$C_{11}\left(C_{22}\right)$ and the Young's moduli along the $x$ and $y$ directions are greater than those of silicon and $\alpha$ quartz. Considering that a vacuum slab is used in the supercell of 1/2-I, the actual value of $C_{11}\left(C_{22}\right)$ should be larger. The thickness of the single slab of $1 / 2$-I is about $2.03 \AA$, while that of the vacuum slab is $3.30 \AA$. So, the real value of $C_{11}\left(C_{22}\right)$ may be greater than $600 \mathrm{GPa}$, comparable to many hard solids.

Hardness is an important parameter for solid materials but is difficult to compute accurately. There are several empirical formulas for the estimation of the hardness of covalent-bonding crystals, e.g., the formulas of Gao et al. [35] and of Ŝimůnek and Vackáŕ [36]. However, neither can be used to estimate the hardness of multilayered materials. Recently, Chen et al. [37] proposed a simple way to estimate the hardness of materials based on their elastic moduli. Using this formula, we estimate the hardness of $1 / 2$-I to be about $20.5 \mathrm{GPa}$. We note here that Chen's formula is mainly tested for 3D crystals and not yet for materials with a multilayered structure. Thus, the estimated hardness of 1/2-I may not be so reliable. Note also that the latest version of USPEX has a module for computing the hardness of materials. The calculated hardness of 1/2-I based on USPEX (4.8 GPa) is much lower than that estimated from the bulk and shear moduli. Such a low value of hardness is most likely due to the weak van der Waals interaction between adjacent slabs. For multislab structures, the strength of a single slab is more relevant. The estimated hardness from the empirical formulas may not describe this property properly.

Another way to estimate the hardness is by computing the ideal strength, regardless of whether the structure is a covalent or multislab solid. Toward this end, we examine 
(a)
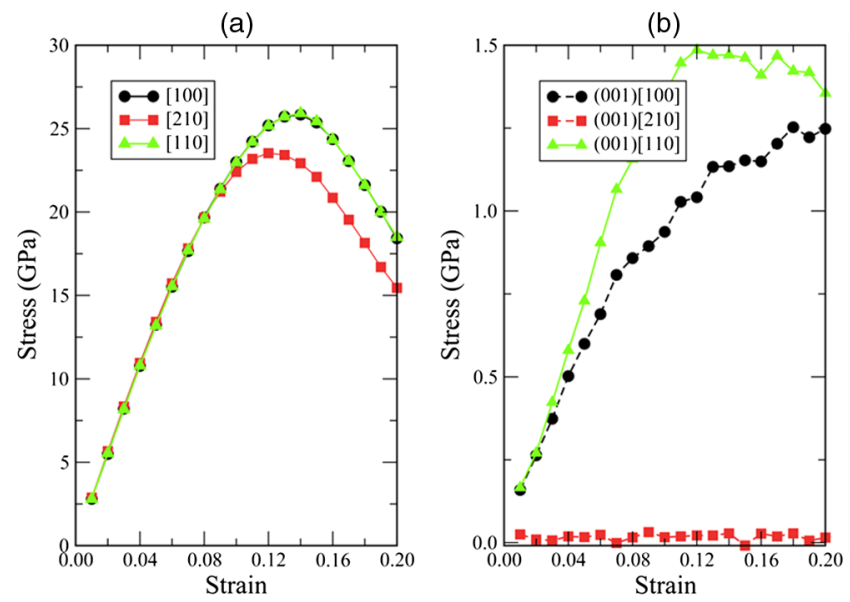

FIG. 6 (color online). Computed stress-strain relations under (a) the tensile load along different directions and (b) the shear load in the (001) plane and along different directions.

the stress-strain relation for the 1/2-I structure under different loads (see Fig. 6). Under tensile loads, the stress increases smoothly at small strain and then turns down as the strain further increases. The maximum stress, known as the ideal tensile strength, is a measure of the resistance toward bond breaking under the tensile load. The ideal tensile strengths of the 1/2-I structure under the tensile loads in the [100], [210], and [110] directions are 25.8, 23.5, and 25.9 GPa, respectively. So, a single slab of 1/2-I is sufficiently strong if used as an insulator intermediate in the nanosized MIS devices. In contrast, the calculated ideal shear strengths are quite small along all the directions considered, suggesting that it is easy to glide along the (001) plane. Thus, the 3D 1/2-I crystal can be an excellent solid lubricant.

\section{Thermal stability}

Thermal stability at high temperature is another important factor for applications of the 1/2-I structure either in nanosized MIS devices or as a solid lubricant, as the typical local temperature can be very high. We examine the thermal stability of the 1/2-I structure using an AIMD simulation, a density-functional-theory-based method implemented in the
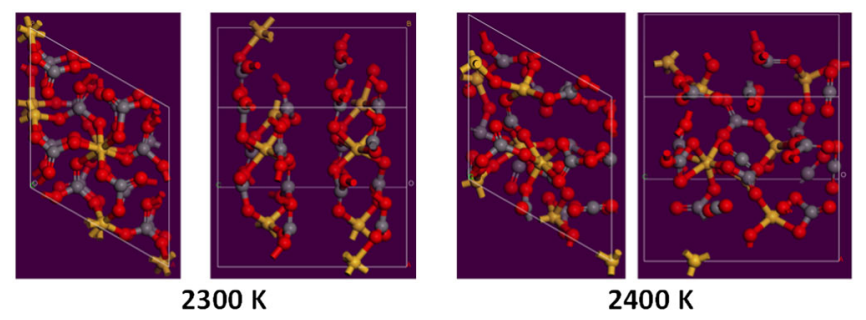

FIG. 7 (color online). Snapshots at the end of 2-ps ab initio molecular-dynamics runs at 2300 and $2400 \mathrm{~K}$, respectively. The left and right panels for each temperature are views along the $x$ and $y$ directions, respectively.
VASP package. Specifically, in the AIMD simulations, a $2 \times 2 \times 2$ supercell containing 72 atoms is used. The canonical ensemble is selected for the simulation. Various temperatures up to $2500 \mathrm{~K}$ are considered. At each temperature, the simulation typically runs for 2 ps with a time step of 2 fs. As shown in Fig. 7, the simulation indicates that the structure is intact until $2400 \mathrm{~K}$. Above $2400 \mathrm{~K}$, the structure is transformed into disordered structures, i.e., begins to melt. Although the AIMD simulation does not give an exact melting point, the temperature at which a structural transition occurs is high enough to show that the 1/2-I structure can be stable below $2300 \mathrm{~K}$.

\section{CONCLUSION}

We have performed an extensive search for the most stable structures of the $\mathrm{Si}_{x} \mathrm{C}_{1-x} \mathrm{O}_{2}$ compound under 20-GPa hydrostatic pressure using an evolutional algorithm. The lowest-enthalpy structure and a number of metastable structures for each given composition are predicted [38]. Based on the low-enthalpy structures, we analyze the chemical-bonding characteristics of $\mathrm{C}, \mathrm{O}$, and $\mathrm{Si}$. We find that $s p^{2}$ hybridization is prevailingly favored for $\mathrm{C}$, and the sixfold coordination is generally favored for $\mathrm{Si}$ in the lowenthalpy structures. The structural features can be very sensitive to the stoichiometric $\mathrm{SiO}_{2} / \mathrm{CO}_{2}$ ratio. When the crystal is rich in $\mathrm{SiO}_{2}$, low-symmetry $3 \mathrm{D}$ structures are energetically favored, and when the crystal is rich in $\mathrm{CO}_{2}$, high-symmetry multislab (or multilayered) structures typically have lower enthalpies and thus are more stable. The calculated formation enthalpies show that the unique 1/2-I structure, a multislab structure for $\mathrm{SiC}_{2} \mathrm{O}_{6}$ (or $\mathrm{Si}_{0.333} \mathrm{C}_{0.667} \mathrm{O}_{2}$ ) with P-3 (147) space-group symmetry, is not only the lowest-enthalpy structure without any imaginary phonon modes, but more importantly is energetically favorable with respect to phase-separated $\mathrm{SiO}_{2}$ and $\mathrm{CO}_{2}$ solids. We also find that the $1 / 2$-I structure possesses a number of valuable properties: It is an insulator with a wide indirect band gap, and it has low shear strength along the slab plane (easy-sliding plane) and excellent thermal stability. With these remarkable properties, the 1/2-I structures may find applications in nanosized MIS devices and as a high-quality solid lubricant or a stable solid-state form for $\mathrm{CO}_{2}$ sequestration. Finally, we note in passing that the structures found in experiments are amorphous or disordered but not crystalline. This is likely because the reaction occurs in the micropores of the $\mathrm{SiO}_{2}$ silicalite with short heating time. Very small ordered structures may form in the local area around the micropores, but the entire matrix may hardly transform into an ordered structure due to the short heating time. It is also possible that multiple crystalline structures coexist due to the closeness in formation enthalpy for some structures (see Figs. 1 and 2). In any event, a longer heating time or repeated heating or annealing may be needed to yield a single-crystalline structure. 


\section{ACKNOWLEDGMENTS}

This work is supported by the National Natural Science Foundation of China (Grant No. 11104056) and the Natural Science Foundation of Anhui Province (Grant No. 11040606Q33). X. C.Z. is supported by ARL (Grant No. W911NF1020099), the NSF (Grant No. DMR0820521), the Nebraska Research Initiative, the University of Nebraska Holland Computing Center, and a grant from USTC for (1000plan) Qianren-B summer research.

[1] M. Santoro and F. A. Gorelli, High Pressure Solid State Chemistry of Carbon Dioxide, Chem. Soc. Rev. 35, 918 (2006).

[2] K. Aoki, H. Yamawaki, M. Sakashita, Y. Gotoh, and K. Takemura, Crystal Structure of the High-Pressure Phase of Solid $\mathrm{CO}_{2}$, Science 263, 356 (1994).

[3] V. M. Giordano and F. Datchi, Molecular Carbon Dioxide at High Pressure and High Temperature, Europhys. Lett. 77, 46002 (2007).

[4] V. Iota, C. S. Yoo, and H. Cynn, Quartzlike Carbon Dioxide: An Optically Nonlinear Extended Solid at High Pressures and Temperatures, Science 283, 1510 (1999).

[5] S. Sera, C. Corazon, G. L. Chiarotti, S. Scandolo, and E. Tossatti, Pressure-Induced Solid Carbonates from Molecular $\mathrm{CO}_{2}$ by Computer Simulation, Science 284, 788 (1999).

[6] C.S. Yoo, H. Cynn, F. Gygi, G. Galli, M. Nicol, D. Hausermann, S. Carlson, and C. Mailhiot, Crystal Structure of Carbon Dioxide at High Pressure: "Superhard" Polymeric Carbon Dioxide, Phys. Rev. Lett. 83, 5527 (1999).

[7] J. Dong, J. K. Tomfohr, and O. Sankey, Rigid Intertetrahedron Angular Interaction of Nonmolecular Carbon Dioxide Solids, Phys. Rev. B 61, 5967 (2000).

[8] J. Dong, J. K. Tomfohr, O. F. Sankey, K. Leinenweber, M. Somayazulu, and P. F. McMillan, Investigation of Hardness in Tetrahedrally Bonded Nonmolecular $\mathrm{CO}_{2}$ Solids by Density-Functional Theory, Phys. Rev. B 62, 14685 (2000).

[9] C. S. Yoo, M. Kim, W. Morgenroth, and P. Liermann, Transformation and Structure of Silicatelike $\mathrm{CO}_{2}-\mathrm{V}$, Phys. Rev. B 87, 214103 (2013).

[10] F. Datchi, B. Mallick, A. Salamat, and S. Ninet, Structure of Polymeric Carbon Dioxide CO2-V, Phys. Rev. Lett. 108, 125701 (2012).

[11] M. Santoro, F. A. Gorelli, R. Bini, J. Haines, O. Combon, C. Levelut, J. A. Montoya, and S. Scandolo, Partially Collapsed Cristobalite Structure in the Non molecular Phase $V$ in $\mathrm{CO}_{2}$, Proc. Natl. Acad. Sci. U.S.A. 109, 5176 (2012).

[12] V. Iota, C. S. Yoo, J. Klepeis, J. Zsolt, W. Evans, and H. Cynn, Six-fold Coordinated Carbon Dioxide VI, Nat. Mater. 6, 34 (2007).

[13] J. Sun, D. D. Klug, R. Mortonak, J. A. Montoya, M. S. Lee, S. Scandolo, and E. Tosatti, High-Pressure Polymeric Phases of Carbon Dioxide, Proc. Natl. Acad. Sci. U.S.A. 106, 6077 (2009).

[14] A. Sengupta and C. S. Yoo, Coesite-like CO2: An Analog to $\mathrm{SiO}_{2}$, Phys. Rev. B 82, 012105 (2010).

[15] A. R. Oganov, S. Ono, Y. Ma, C. W. Glass, and A. Garcia, Novel High-Pressure Structures of $\mathrm{MgCO}_{3}, \mathrm{CaCO}_{3}$ and
$\mathrm{CO}_{2}$ and Their Role in the Earth's Lower Mantle, Earth Planet. Sci. Lett. 273, 38 (2008).

[16] M. Santoro, F. A. Gorelli, R. Bini, G. Ruocco, S. Scandolo, and W. A. Crichton, Amorphous Silica-like Carbon Dioxide, Nature (London) 441, 857 (2006).

[17] J. A. Montoya, R. Rousseau, M. Santoro, F. Gorelli, and S. Scandolo, Mixed Threefold and Fourfold Carbon Coordination in Compressed $\mathrm{CO}_{2}$, Phys. Rev. Lett. 100, 163002 (2008).

[18] F. Liu, S. H. Garofalini, D. King-Smith, and D. Vanderbilt, First-Principles Study of Crystalline Silica, Phys. Rev. B 49, 12528 (1994).

[19] A. Aravindh et al., $\mathrm{Si}_{x} \mathrm{C}_{1-x} \mathrm{O}_{2}$ Alloys: A Possible Route to Stabilize Carbon-Based Silica-like Solids?, Solid State Commun. 144, 273 (2007).

[20] M. Santoro, F. Gorelli, J. Haines, O. Cambon, C. Levelut, and G. Garbarino, Silicon Carbonate Phase Formed from Carbon Dioxide and Silica under Pressure, Proc. Natl. Acad. Sci. U.S.A. 108, 7689 (2011).

[21] A. Morales-García, M. Marqués, J. M. Menéndez, D. Santamaría-Pérez, V. G. Baonza, and J. M. Recio, FirstPrinciples Study of Structure and Stability in Si-C-O Based Materials, Theor. Chem. Acc. 132, 1308 (2013).

[22] A. R. Oganov and C. W. Glass, Crystal Structure Prediction Using Ab Initio Evolutionary Techniques: Principles and Applications, J. Chem. Phys. 124, 244704 (2006).

[23] A. R. Oganov, A. O. Lyakhov, and M. Valle, How Evolutionary Crystal Structure Prediction Worksand Why, Acc. Chem. Res. 44, 227 (2011).

[24] Modern Methods of Crystal Structure Prediction, edited by A. R. Oganov (Wiley-VCH, Berlin, 2010).

[25] R. L. Zhou and X.C. Zeng, Polymorphic Phases of sp3-Hybridized Carbon under Cold Compression, J. Am. Chem. Soc. 134, 7530 (2012).

[26] G. Kresse and J. Furthmüller, Efficient Iterative Schemes for Ab Initio Total-Energy Calculations Using a Plane-Wave Basis Set, Phys. Rev. B 54, 11169 (1996).

[27] J. P. Perdew and A. Zunger, Self-Interaction Correction to Density-Functional Approximations for Many-Electron Systems, Phys. Rev. B 23, 5048 (1981).

[28] A. Togo, F. Oba, and I. Tanaka, First-Principles Calculations of the Ferroelastic Transition between Rutile-Type and $\mathrm{CaCl}_{2}$-Type $\mathrm{SiO}_{2}$ at High Pressures, Phys. Rev. B 78, 134106 (2008).

[29] J. R. Smyth, R. J. Swope, and A. R. Pawley, H in RutileType Compounds: II. Crystal Chemistry of Al Substitution in H-Bearing Stishovite., Am. Mineral. 80, 454 (1995).

[30] S. J. Clark, M. D. Segall, C. J. Pickard, P. J. Hasnip, M. I. J. Probert, K. Refson, and M. C. Payne, First Principles Methods Using CASTEP, Z. Kristallogr. 220, 567 (2005).

[31] M. Segall, P. Lindan, M. Probert, C. Pickard, P. Hasnip, S. Clark, and J. Payne, First-Principles Simulation: Ideas, Illustrations and the CASTEP Code, J. Phys. Condens. Matter 14, 2717 (2002).

[32] D. Vanderbilt, Soft Self-Consistent Pseudopotentials in a Generalized Eigenvalue Formalism, Phys. Rev. B 41, 7892 (1990).

[33] J. Heyd, G. E. Scuseria, and M. Ernzerhof, Hybrid Functionals Based on a Screened Coulomb Potential, J. Chem. 
Phys. 118, 8207 (2003); Hybrid Functionals Based on a Screened Coulomb Potential, 124, 219906(E) (2006).

[34] J. Heyd and G. E. Scuseria, Efficient Hybrid Density Functional Calculations in Solids: Assessment of the HeydScuseria-Ernzerhof Screened Coulomb Hybrid Functional, J. Chem. Phys. 121, 1187 (2004).

[35] F. Gao, J. He, E. Wu, S. Liu, D. Yu, D. Li, S. Zhang, and Y. Tian, Hardness of Covalent Crystals, Phys. Rev. Lett. 91, 015502 (2003).
[36] A. Šimůnek and J. Vackár̆, Hardness of Covalent, and Ionic Crystals: First-Principle Calculations, Phys. Rev. Lett. 96, 085501 (2006).

[37] X.-Q. Chen, H. Niu, D. Li, and Y. Li, Modeling Hardness of Polycrystalline Materials and Bulk Metallic Glasses, Intermetallics 19, 1275 (2011).

[38] See Supplemental Material at http://link.aps.org/ supplemental/10.1103/PhysRevX.4.011030 for crystalline data of the predicted solid structures. 